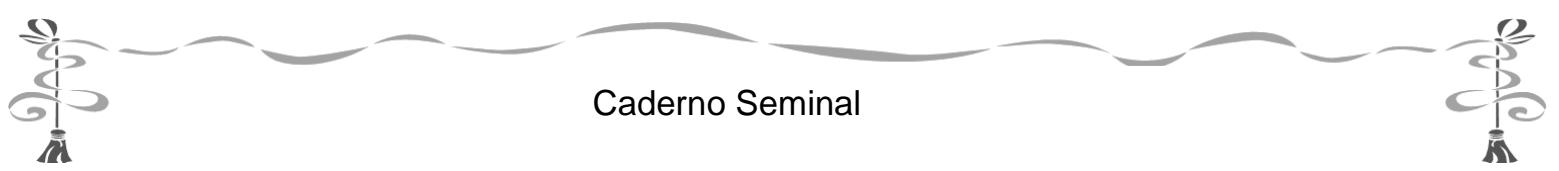

\title{
EDITORIAIS DE EDICCÕES ESPECIAIS “VERDES” NA IMPRENSA PERIÓDICA PORTUGUESA CONTEMPORÂNEA. O CASO DA REVISTA "VISÃO"93
}

\author{
EDITORIALS OF "GREEN" SPECIAL EDITIONS IN PORTUGUESE CONTEMPORARY \\ PERIODICAL PRESS. THE CASE OF THE MAGAZINE "VISÃO"
}

Rui Ramos ${ }^{94}$

\section{Resumo}

O discurso sobre o ambiente percorre múltiplas linhas na esfera pública contemporânea. Trata-se de um "publicly dominant discourse" (Jung 2001: 271), um tipo de discurso significativo na configuração das experiências "em segunda mão" mediadas pelos media, com relevante capacidade de intervenção social.

Uma das manifestações desse discurso pode ser identificada nos editoriais da imprensa escrita. Textos assumidamente opinativos, constroem-se sobre uma retórica própria e frequentemente visam à mobilização dos cidadãos, sendo interessante, dos pontos de vista científico e social, a sua desconstrução e análise.

Assumindo estes pressupostos, o presente texto analisa, no quadro da Análise do Discurso e de um ponto de vista enunciativo e argumentativo, os editoriais das edições especiais "verdes" da revista portuguesa Visão, nos seis anos em que esta publicou estes números especiais (2007 a 2012). Procura identificar as suas linhas de organização textual, a sua orientação pragmática, os quadros conceptuais sobre os quais se constrói a sua retórica e os jogos enunciativos de que se socorrem.

Palavras-chave: Ambientalismo, Opinião, Enunciação, Editorial, Imprensa.

\section{Abstract}

The discourse on the environment runs multiple lines in contemporary public sphere. This is a "publicly dominant discourse" (Jung 2001: 271), a type of relevant discourse in shaping "second hand" experiences mediated by the media, with significant capacity of social intervention.

Some of the evidences of this discourse can be found in the press editorials. They are texts manifesting a personal opinion, built on a specific rhetoric and very often aimed at mobilizing citizens, and its deconstruction and analysis is interesting from a scientific and social point of view. On this basis, this paper analyses, within the framework of Discourse Analysis and paying special attention to enunciation and argumentation, the editorials of the "green" special editions of the Portuguese magazine "Visão", during its six years of publication (2007 to 2012). The paper intends to identify their lines of text organization, its pragmatic orientation, the frames associated to their rhetoric and the enunciative features that they rely upon.

Keywords: environmentalism, opinion, enunciation, editorial, press

\footnotetext{
${ }^{93}$ Nota da editora: Manteve-se a grafia lusitana.

${ }^{94}$ Rui Ramos é doutor em Linguística, professor do Instituto de Educação e investigador do Centro de Investigação em Estudos da Criança da Universidade do Minho (Portugal). Tem dedicado especial atenção ao estudo do discurso sobre o ambiente, no quadro da Análise do Discurso. Mais informações em http://ruiramos.do.sapo.pt
}

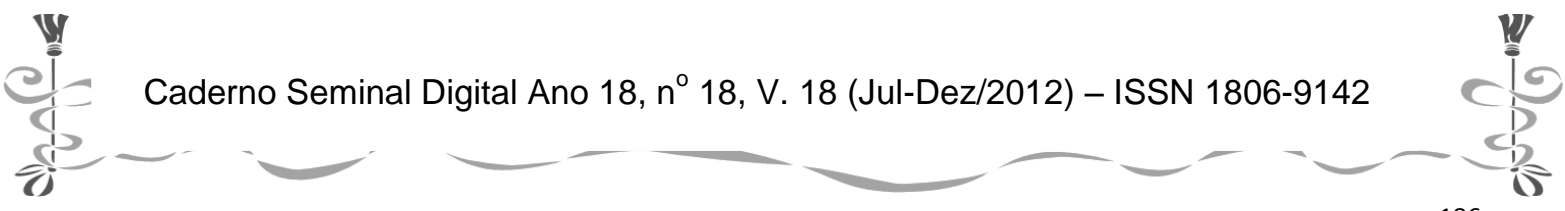




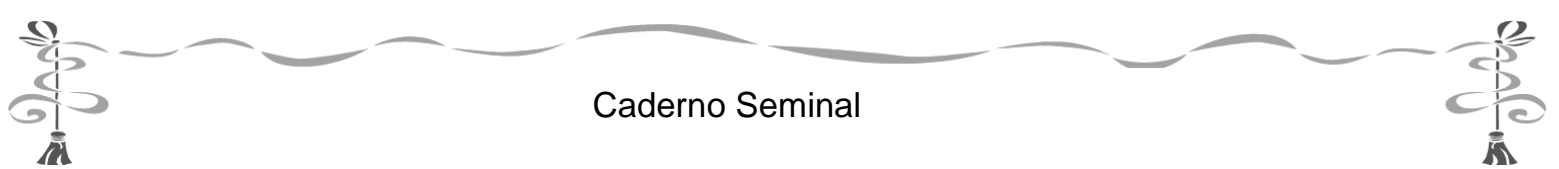

\section{Introdução}

Nas modernas sociedades ocidentais, um dos poderes reconhecidamente operantes no devir social é o dos media. Constituindo-se como instâncias de intervenção social, estes atraem a atenção dos seus destinatários para mediar, filtrar e dar sentido aos factos sociais brutos, transformando-os em eventos mediáticos (Charaudeau, 1997), revelando uns e, simultaneamente, esbatendo outros segmentos do real. Envolvem, na focalização operada, os olhares, as perceções e a ação dos cidadãos, objetivando a realidade. Desta forma, os meios de comunicação social comportamse como atores estratégicos, configuram valores e práticas dos cidadãos, definem prioridades sociais e agendam a vida social.

Entre os discursos mediáticos de grande impacto, testemunhando o seu lugar de relevo na esfera pública, conta-se o discurso sobre o ambiente. Este pode mesmo definido como um "publicly dominant discourse" (Jung 2001, p. 271), um tipo de discurso significativo na configuração das experiências "em segunda mão" mediadas pelos media, com relevante capacidade de intervenção social transversal, influenciando o discurso, a ideologia e as opiniões e ações de cada cidadão.

A análise das manifestações discursivas do ambientalismo nos media, no quadro da moderna Análise do Discurso e reconhecendo especial relevo às questões enunciativas e argumentativas, que neste estudo se desenvolve, poderá colaborar na desconstrução e leitura aprofundada do discurso sobre o ambiente, permitindo traçar as marcas mais salientes da sua estrutura e do seu funcionamento.

\section{Córpus e Metodologia}

O córpus de análise deste estudo compreende seis editoriais das edições "verdes" da revista Visão, uma publicação semanal de qualidade no panorama jornalístico português. Esta revista publica, desde outubro de 2007, uma edição especial por ano dedicada à questão ambiental, designada "edição verde", com um tema específico dentro da temática ecológica geral.

Os seis editoriais, presentes nas primeiras páginas de cada edição, fazem a contextualização preliminar e preparam a leitura, justificam a iniciativa, anunciam o rumo discursivo geral, traçam expectativas e estabelecem as bases sobre as quais funcionará a sua dimensão pragmática. O primeiro destes apresenta genericamente a iniciativa e promete a sua continuidade no tempo:

(1) (...) "uma edição 'Verde', a realizar todos os anos, o ponto alto de uma revista que considera importante acompanhar as questões do

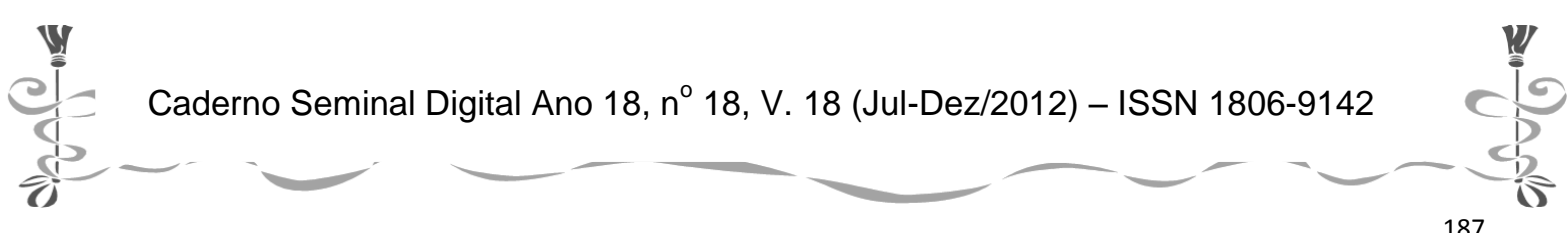




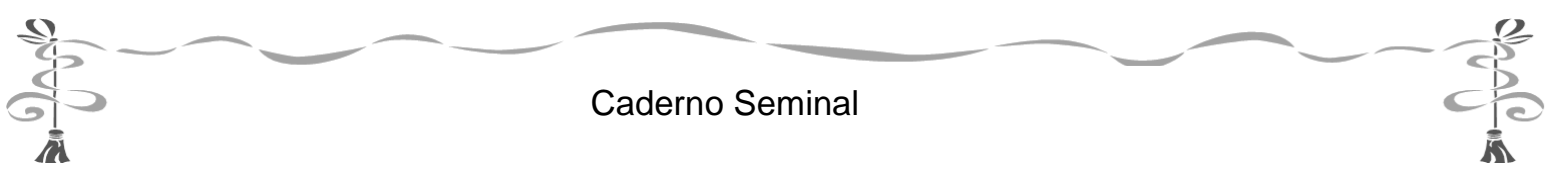

ambiente e quer participar no esforço global para garantir um planeta viável" (Visão, 2007, p. 13) ${ }^{95}$.

São, então, textos assumidamente opinativos, textos "terceiros" porque construídos sobre outros discursos, marcados por uma retórica própria e por segmentos justificativos e de modalidade deôntica, com uma orientação prospetiva relativamente ao restante material jornalístico (e mesmo publicitário) que cada edição apresenta, e ainda por uma orientação pragmática específica, já manifestada no segmento recortado acima.

A metodologia passa pela identificação dos frames e das linhas de desenvolvimento mais salientes na organização interna dos textos. Em alguns casos, identificar-se-á o reportório interpretativo mais produtivo na construção do sentido. Recorre-se a uma perspetiva enunciativa e da pragmática linguística, essencialmente na linha da chamada "escola francesa da Análise do Discurso".

\section{AS EVIDÊNCIAS O estatuto dos textos}

Os textos são neste estudo identificados como editoriais, mas eles não se apresentam explicitamente com esse estatuto. Surgem, como foi referido, nas páginas iniciais de cada edição (pp. 12-13, 6, 6, 5, 4 e 5 em 2007, 2008, 2009, 2010, 2011 e 2012 respetivamente), numa rubrica designada Linha Direta - a primeira rubrica editorial, após a capa, a página com o índice e os destaques (títulos e brevíssimas súmulas) e as páginas com publicidade. Os de 2008 e 2011 não são assinados, sendo assim "da redação"; os restantes são assinados pelo diretor da revista. Poderá, portanto, ser-lhes atribuído a todos um valor orientador e explicitador da política editorial e, portanto, de primeiras chaves de interpretação dos textos que se seguirão. Neste sentido, e ao nível da organização interna da publicação, assumem um valor catafórico, explicitado em alguns segmentos, como exemplifica o extrato seguinte:

(2) Nesta VISÃO Verde, damos-lhe conta do quadro político global (...). $\mathrm{E}$, aqui, destaque para o esclarecedor texto que o presidente da Comissão Europeia, Durão Barroso, escreveu especialmente para esta edição. (...) Nesta edição, mostramos-lhe igualmente o «pano de fundo» que enquadra os palcos negociais da grande política internacional. (Visão, 2007, p. 12-13)

Além disso, a designação da rubrica ("Linha direta") evidencia uma dimensão que os marca fortemente: trata-se de um convite explícito à comunicação "direta" com o leitor. O jornalista / enunciador simula uma interação verbal próxima, mesmo

\footnotetext{
${ }^{95}$ Todas as citações do córpus viram atualizadas a sua escrita pela norma ortográfica mais recente, decorrente do Acordo Ortográfico de 1990.
}

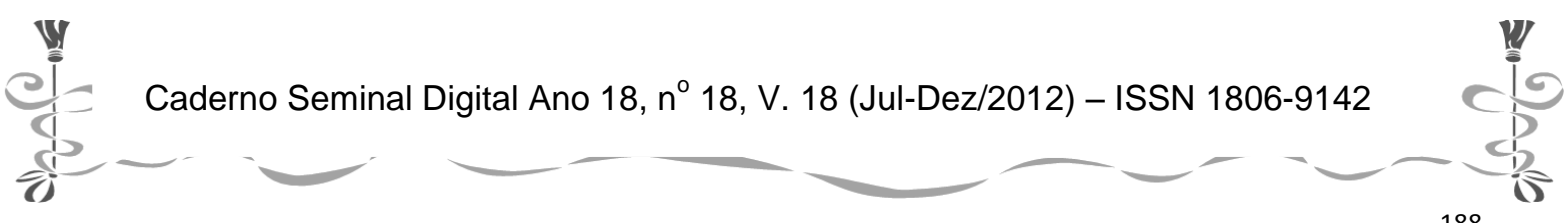




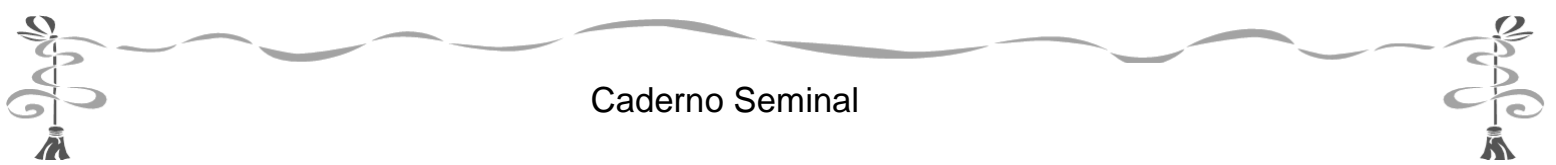

íntima e individual, com cada leitor / enunciatário, uma sequência preparatória ou inicial para a realização do macroato ilocutório que se concretizará com a troca verbal que os restantes textos corporizam. Em (2), acima, a criação da relação de comunicação direta está bem patente no uso das formas verbais "damos-lhe" e "mostramos-lhe", convocando explicitamente o leitor para o jogo dialógico.

Há que assinalar, igualmente, a heterogeneidade formal ou semiótica (Moirand, 1999) dos textos em análise: o primeiro é relativamente longo, prolongando-se por duas páginas; o segundo é extremamente curto, composto por não mais de dois breves parágrafos; os dois seguintes ocupam uma página; o penúltimo cerca de meia página e o último ocupa de novo uma página. Terá havido, portanto, variação na atribuição da função específica aos textos em causa na economia interna das publicações, destacando-se a edição de 2008, claramente o mais breve e mais dificilmente classificável como editorial.

\section{O tema central de cada edição}

Em cada ano, a edição respetiva seleciona um "tema" específico dentro da vasta questão ambiental. Esse tema é anunciado nos textos em análise e concretiza-se nos vários tipos de artigos de cada edição, nas ilustrações, nos grafismos de capa, etc. A análise conjunta permite identificar quais as áreas da vida política, social e individual dominantemente associadas pela publicação às questões ambientais. Assim, em 2007 o tema agregador foi genericamente o das ameaças das alterações climáticas, com ênfase na floresta, mas em 2008 foi especificamente o dos oceanos em risco, em 2009 a vida urbana, em 2010 a cidadania responsável, em 2011 os recursos agrícolas e em 2012 a relação entre ecologia e economia.

Estas escolhas não suscitam especial surpresa, pois trata-se de motivos frequentes no interdiscurso ambiental e nas preocupações coletivas. Estes tópicos são assíduos na discussão e ocupam lugares de relevo no quadro da problemática ambiental global.

\section{Reificação e catastrofismo}

Os textos em análise organizam-se sobre um topos recorrente: o da reificação dos estados de coisas não percetíveis pela experiência individual. Os fenómenos associados às alterações climáticas não são, na sua generalidade, percetíveis pelos sentidos de forma imediata. A sua escala temporal é muito longa, substancialmente diferente dos nossos ritmos e limites cronológicos e, em parte por isso, não nos apercebemos deles com facilidade. Os textos reificam-nos, materializam-nos, apontando manifestações concretas e percetíveis que associam e enquadram no fenómeno mais vasto, como se verifica nos segmentos seguintes:

(3) Assistimos, em direto, aos efeitos devastadores causados pelo tsunami de 2004, numa vasta zona do mundo. E, quase a par e passo, ao

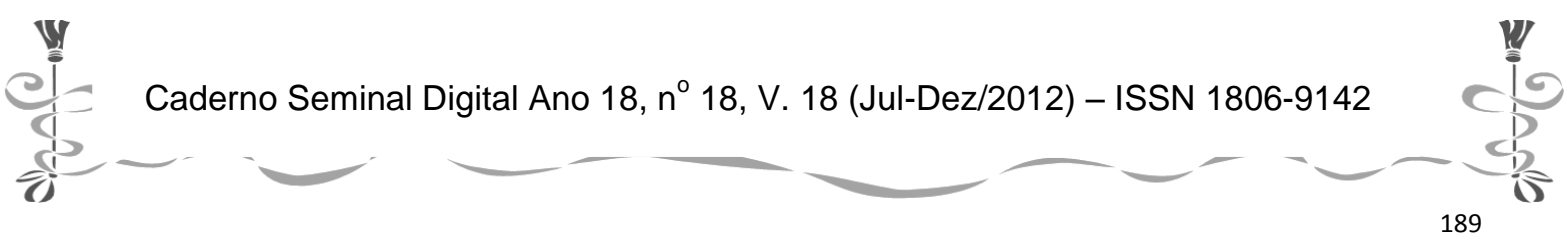




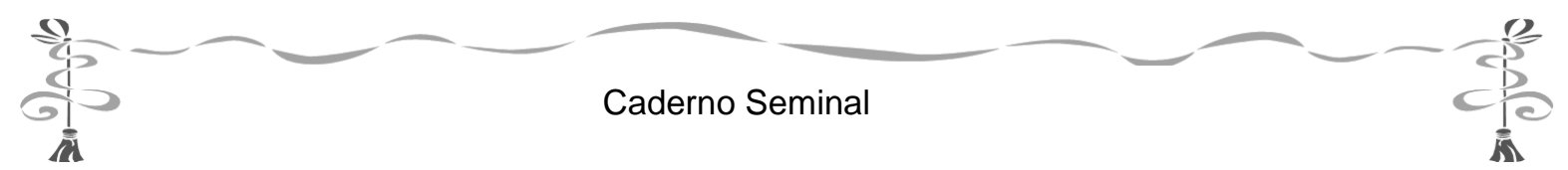

furacão Katrina, em 2005, e ao caos que se abateu sobre Nova Orleães. (Visão, 2007, p. 12)

(4) Sob várias formas, das enxurradas às grandes secas, das ondas de frio aos recordes de calor as manifestações extremas da natureza repetem-se, com mais violência, a intervalos cada vez mais curtos. (Visão, 2010, p. 5)

Nestes dois segmentos, manifestações concretas de fenómenos naturais são evocadas para lembrar a força dos elementos e a fragilidade individual e das estruturas sociais para se lhes opor. A proximidade entre os fenómenos e os cidadãos é marcada pelo uso do Presente, em (4). No primeiro caso, a modificação do verbo "assistir" pelo adverbial "em direto" reforça a proximidade temporal e tende a anular a distância física, ao menos simbolicamente; no segundo caso, a dupla gradação do aumento da violência e do aumento da frequência potencia o dramatismo ${ }^{96}$.

Acresce que esse dramatismo é fortemente intensificado por outros recursos, entre os quais há que assinalar um reportório interpretativo muito saliente. Só no primeiro texto da série em análise, a lexemas como "devastadores" ou "caos", presentes no segmento (3), há que adicionar um conjunto importante de outros, como "assustadora", "catástrofe", "horror", "urgência", "tragédias", "colapso", "pobreza", "doença", "fome”, "migrações em massa” (Visão, 2007, p. 12). Do semantismo de "abateu", em (3), decorre igualmente a criação de um frame de violência.

De entre os lexemas criadores de frames de risco e tragédia, sobressai um grupo específico: aqueles que, sendo formados pela adição de prefixos de negação / oposição, colaboram na construção de cenários negativos: "desordens climáticas", "danos irreparáveis", "custos ambientais, económicos e sociais incomportáveis", "mudanças (...) impossiveis”, "peso incontornável”, (Visão, 2007, p. 12-13); “o nosso estilo de vida (...) é incomportávep", "o consumo de recursos naturais (...) exige o impossivel", "danos irreparáveis", "um quadro insustentável", "procura (...) interminável de aumento da produção e do consumo", "mundo desigual” (Visão, 2010, p. 5); “esforço coletivo indispensável", "futuro incerto" (Visão, 2011, p. 4); "crescimento demográfico mundial incomportável", "ainda mais incomportáveis e perigosos" (Visão, 2012, p. 5 ) 97. Note-se alguma repetição de termos e expressões de edição para edição, o que sugere a existência de um vocabulário especializado, reiteradamente utilizado no discurso ambiental, e que vai para além dos termos técnicos tomados ao discurso técnico-científico.

Estes usos evocam cenários de dissenso e fricção de vozes, de conflito verbal, pela convocação implícita de outras enunciações, virtuais ou efetivas, de orientação

\footnotetext{
${ }^{96}$ Sobre dramatização e discurso apocalíptico no discurso ambiental, ver Foust e Murphy, 2009 e Ramos, 2011.

${ }^{97}$ Todos os itálicos da lista são nossos.
}

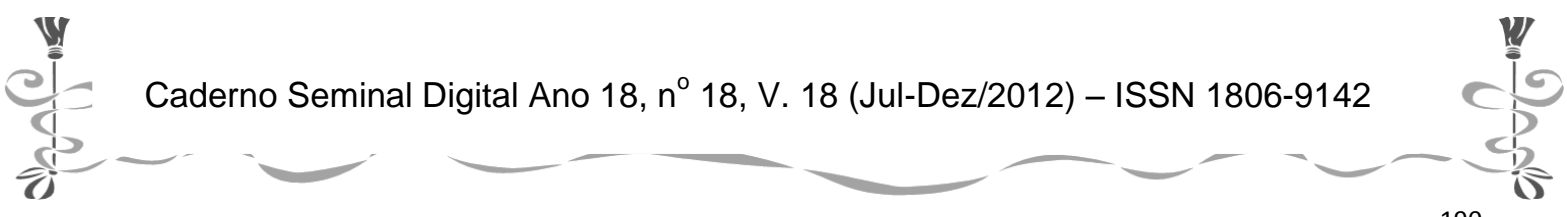




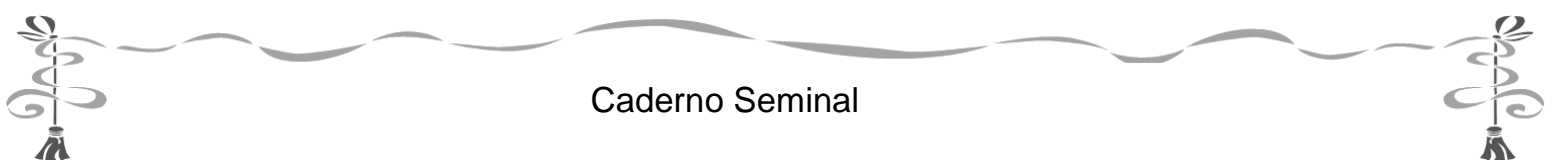

argumentativa eufórica, suplantadas na leitura dos estados de coisas por cenários disfóricos. Trata-se do uso de uma forma de negação polémica, testemunhando o dialogismo primordial ${ }^{98}$ da língua e o caráter polémico do ambientalismo.

\section{Presença interdiscursiva da ciência}

Um outro traço frequente do discurso sobre o ambiente reside na presença interdiscursiva da ciência ${ }^{99}$. De uma forma insistente, os dois discursos interpenetram-se no tratamento de questões ambientais, fornecendo aquela parte do vocabulário, a tendência para a monossemização, a sintaxe preferencial e os modos de organização discursiva. Nos artigos em análise, provavelmente por se tratar de textos jornalísticos pertencentes ao género de enunciação subjetivizada (Moirand, 1999), essa presença não é particularmente forte e o discurso da ciência manifesta-se de forma discreta em alusões a estudos mas, de forma mais visível, ao recurso a quantificações exatas e raciocínios matemáticos, como o segmento seguinte ilustra:

(5) O consumo de recursos naturais pelos pouco mais de seis mil milhões de habitantes do planeta exige o impossível: a existência de uma Terra e meia. (...) Um quadro insustentável que atingirá um valor absurdo de 2,8 planetas de 2050, caso se mantenham os padrões de consumo atuais e a linha de crescimento da população mundial, que passará para cerca de 9 mil milhões de pessoas dentro de 40 anos. (Visão, 2010, p. 5)

Neste segmento, não só pode identificar-se a presença de quantificações, mas o próprio raciocínio de proporcionalidade, que dá fundamento à projeção no futuro.

Há que assinalar que o uso de quantificações pode ter um valor específico, como sublinha van Dijk (1988) e, por exemplo, na sua senda, Koetsenruijter (2008): podem estar dominantemente ao serviço do reforço de credibilidade e não corresponderem exatamente a um desejo de informação exaustiva. Neste caso, contribuem igualmente para a dramatização, ao desenhar frames marcados por grandezas em alto grau, mas difíceis de apreender no seu efetivo valor.

\section{Projeções}

Outro traço fortemente operativo no discurso ambiental e também identificável no córpus recortado é a presença de calibrações temporais e projeções no futuro ${ }^{100}$ (como a que acabou de ser apresentada em (5)). O primeiro artigo da série analisada abre com uma estratégia deste teor:

\footnotetext{
${ }^{98}$ Cf.: Bakhtine, 1981 (1930); Fonseca, 1994; Moirand, 1999.

${ }^{99}$ Cf.: Ramos e Carvalho, 2008; Ramos, 2009.

${ }^{100}$ Cf.: Harré, Brockmeier e Mühlhäusler, 1999.
}

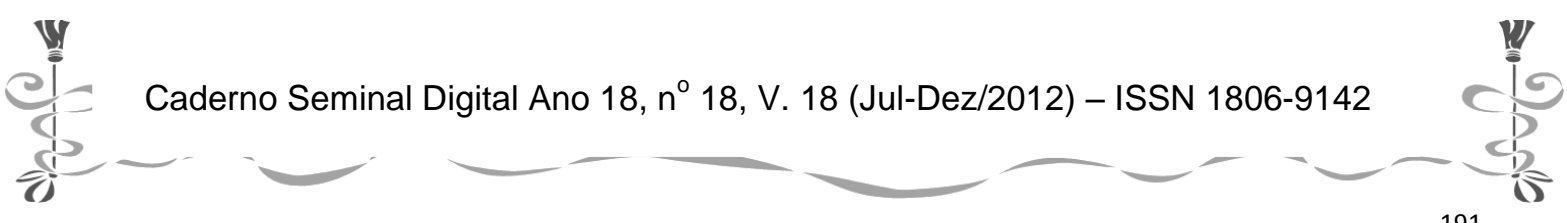




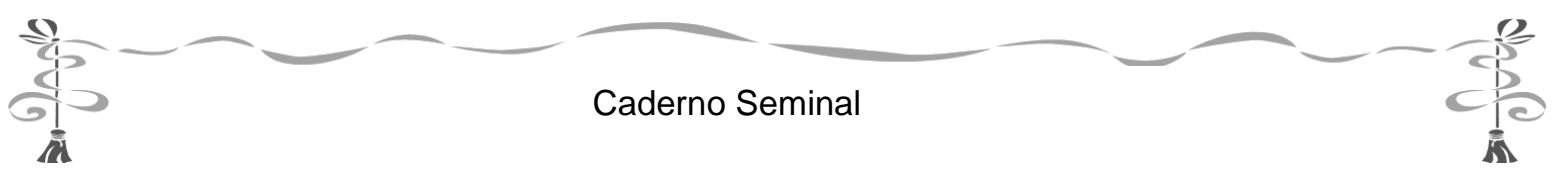

(6) Desordens climáticas capazes de causar danos irreparáveis no equilíbrio global do Planeta deixaram de ser tema de filmes de ficção científica para se aproximarem perigosamente da realidade que nos espera a breve prazo. (...)

Apesar das nossas limitações para antecipar o horror que nos pode estar destinado daqui a quatro ou cinco décadas, estamos hoje, mais do que nunca, conscientes da urgência de mudar o nosso paradigma de desenvolvimento económico e social, sob pena de termos de começar a pagar, já «amanhã», custos ambientais, económicos e sociais incomportáveis. (Visão, 2007, p. 12)

Mas também outros artigos elaboram projeções no futuro, de forma mais ou menos marcada:

(7) Deve, por isso, servir também de inspiração a todo o tipo de decisores, (...) que podem, de alguma forma, condicionar o futuro das nossas cidades - o futuro da nossa economia e do nosso bem-estar. (Visão, 2009, p. 6)

(8) A Terra já passou por ciclos de grande convulsão climática e sofreu profundas alterações ambientais, ao longo da sua existência (...). Mas nunca, como hoje, o planeta esteve em risco, devido ao comportamento de uma única espécie. O que estamos a fazer, e o que podemos fazer, para inverter a situação que criámos? (...)

Mesmo que, um dia, o aquecimento global seja controlado, o planeta em que vivemos não aguentará, entretanto, a pressão que hoje sofre. (Visão, 2010 , p. 6)

Nos segmentos selecionados, verifica-se a perspetivação do tempo entre passadopresente e futuro, sendo que o foco é o de olhar o futuro e mudar de comportamento no presente. A evocação do passado, identificável em (8), corresponde a uma estratégia de reforço argumentativo, com uma estrutura escalar, para dramatizar a situação presente (num grau de risco inscrito num ponto extremo da escala construída), o que intensifica a orientação para a conclusão sugerida: é absolutamente obrigatório "inverter a situação que criámos". Se não for por vontade própria, será mesmo pela força derradeira das circunstâncias, como se pode ler no último parágrafo desse segmento - ideia também presente no final de (6).

Neste caso, é identificável alguma gradação no discurso entre 2007 e a atualidade. Se o texto de 2007 deixa alguma margem de dúvida, inscrevendo os estados de coisas em períodos temporais futuros mas relativamente próximos ("a breve prazo", "daqui a quatro ou cinco décadas", "«amanhã»" grafado com aspas), e de o assumir da verdade da asserção acerca dos estados de coisas futuros ser atenuada em "pode estar destinado", no texto de 2010 é dado como adquirido que os efeitos do modo de vida do homem sobre o ambiente são negativos e incontornáveis - note-se que os estados de coisas disfóricos são inscritos no passado ("criámos"), conferindo-lhes uma existência real e inegável, e o desenho dos estados de coisas futuros é também

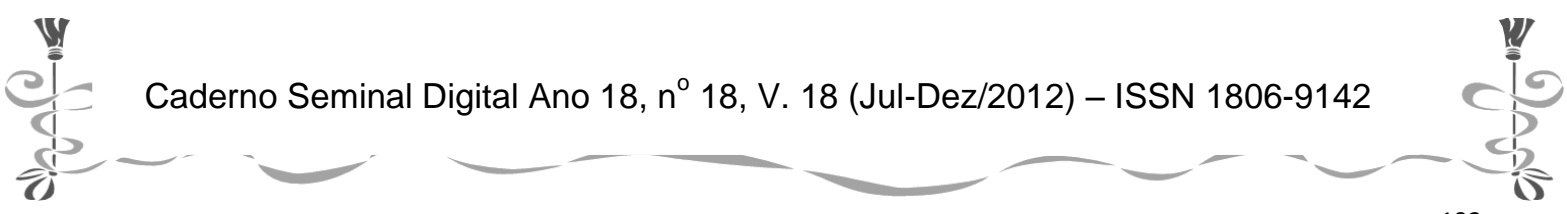




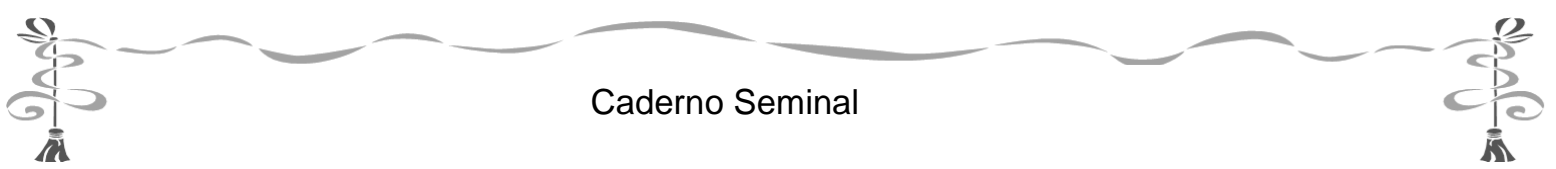

plenamente assumido, sem atenuação enunciativa. $\mathrm{O}$ mesmo pode ser identificado no mais recente dos textos analisados:

(9) Um crescimento demográfico mundial incomportável, a entrada de camadas cada vez mais largas da população global nos padrões de consumo das sociedades desenvolvidas e uma procura sempre crescente de energia tornam a pressão sobre os recursos naturais e os níveis de poluição ainda mais incomportáveis e perigosos. (...) Tudo isto são razões para que o mundo mude rapidamente de comportamento. Mudará mal, por força das catástrofes naturais que já sofremos e que continuarão a aumentar de ritmo e intensidade, ou, desejavelmente, mudará bem, por força de um novo modo de olhar para o mundo. (Visão, 2012, p. 5)

O que este excerto mostra é a certeza quanto ao quadro futuro, realizando um ato preditivo de cuja veracidade o enunciador se assume plenamente como garante, manifestada pelo Futuro verbal em "mudará", repetido, marcando a estrutura paralelística que assenta na evocação da fórmula "a bem ou a mal": "mudará mal, por força das..." ou "mudará bem, por força de...".

Esta fórmula pode construir dois frames: por um lado, um frame em que o enunciador se compromete na tentativa de concretização de eventos futuros, se o estado de coisas configurado estiver dentro das suas possibilidades de ação; por outro lado, um outro frame caraterizado pela inevitabilidade, pela certeza da concretização de um determinado estado de coisas, independentemente da vontade do enunciador. Aliás, pode mesmo afirmar-se que, tipicamente, esse estado de coisas é contrário aos melhores desejos do enunciador e/ou do enunciatário. Neste último caso, verifica-se a realização de um ato ilocutório de ameaça.

É o segundo cenário que se configura neste caso: o enunciador dá como certo e seguro que o mundo mudará "rapidamente de comportamento", a bem ou a mal. E, com este artifício argumentativo, o enunciador não só dá como certo que o mundo mudará, mas dá também força aos argumentos que estão na base dessa mudança, dada como consabida e indiscutível: há um conjunto incontornável de "razões", sumariadas na frase inicial de (9).

Como pode verificar-se, esta posição do enunciador é marcadamente distinta da que era por ele assumida nos artigos iniciais das edições em análise: o mesmo tipo de argumento existe (confronte-se com (6)), mas a atenuação enunciativa e a dúvida são transformadas em reforço e certezas.

\section{A Dimensão Agónica}

Sistematicamente presente no discurso ambiental, do mais empenhado ao mais isento, a ideia de luta e de preservação (sempre uma preservação contra algo ou alguém) manifesta-se igualmente no córpus. O vocabulário do campo jurídico ou da guerra está presente, como pode verificar-se nos excertos seguintes:

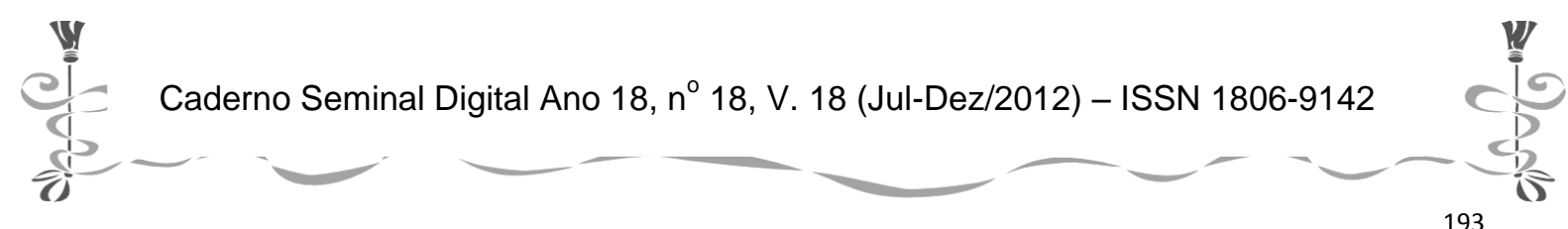




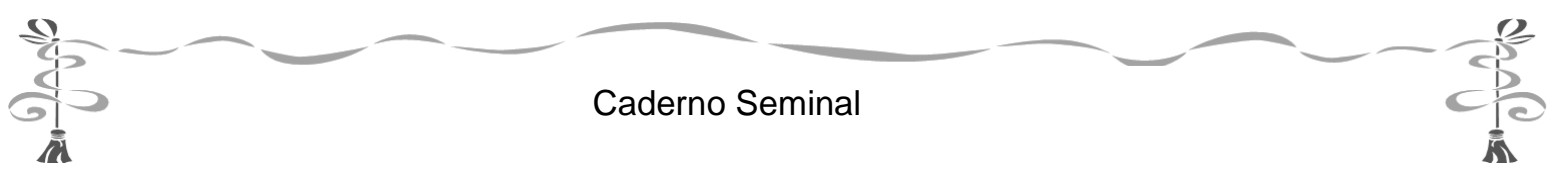

(10) Uma realidade que passa por muitas ameaças e atentados ao ambiente, como os crimes cometidos no coração da Amazónia (...). Mas também pelos esforços de um crescente grupo de pessoas que (...) se batem pela adoção de novos comportamentos e regras em prol do ambiente (...).

A defesa do ambiente é, na verdade, uma guerra de todos. (Visão, 2007, p. 13)

(11) Numa época marcada pela ameaça das alterações climáticas, a defesa da vida nos oceanos (...) (Visão, 2008, p. 6)

Apresentado desta forma, ao nível mais ou menos abstrato da defesa de um bem, sem explicitar e aprofundar ou concretizar as situações e sem apontar alvos específicos, parece impossível discordar de quem proclama a necessidade de unir esforços a favor da natureza e contra os que a põem em perigo. A natureza ou, em geral, o ambiente surgem como vítimas de "ameaças", "atentados" ou "crimes", o que cria um frame com imediata identificação dos papéis, pelo menos do papel da natureza como vítima. A nossa quase natural propensão para a defesa dos pobres e oprimidos, das vítimas (e quanto mais indefesa e/ou inocente, melhor) impele o leitor a colocar-se no lado da tribuna em que se encontra o ameaçado, o agredido, a vítima, num movimento mais ou menos ideal de busca da justiça e do bem-estar coletivo. A dimensão agónica do ambientalismo está patente de forma bem visível no vocabulário, em todos os textos analisados.

\section{Ethos e diretividade}

Em estreita relação com o tópico anterior, uma estratégia particularmente saliente na construção dos artigos em causa é a forte identificação entre jornalista / enunciador e leitor / enunciatário.

Esta inscreve-se na lógica de um topos igualmente recorrente no discurso ambiental, o que une todos os ecossistemas e seus habitantes no mesmo destino comum. Aliás, a expressão "our commom future", título do também designado Relatório Bruntland, de 1987, que traçou a definição de desenvolvimento sustentável como aquele que satisfaz as necessidades das gerações presentes sem comprometer a capacidade das futuras de suprir suas próprias necessidades, ilustra adequadamente essa visão global em termos de espaço, unindo todos os elementos integrantes do ecossistema planetário, e em termos de tempo, alargando a perspetiva para além do imediato.

Exemplificam este recurso vários dos segmentos acima apresentados: "assistimos" em (3), ou os vários usos verbais da primeira pessoa do plural e os pronomes com o mesmo valor em (6), as formas do determinante "nossas" / "nossa" / "nosso" em (7) e, de novo, os usos da primeira pessoa do plural em (8). Esta é uma estratégia presente em todos os textos do córpus, mesmo no brevíssimo artigo da edição de

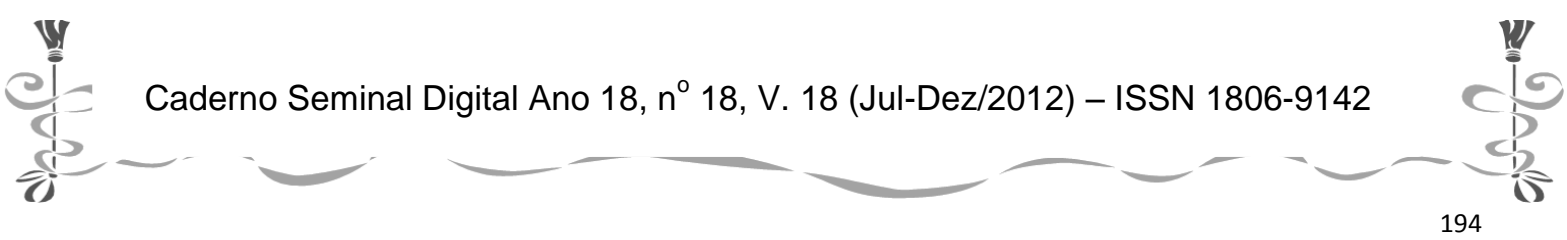




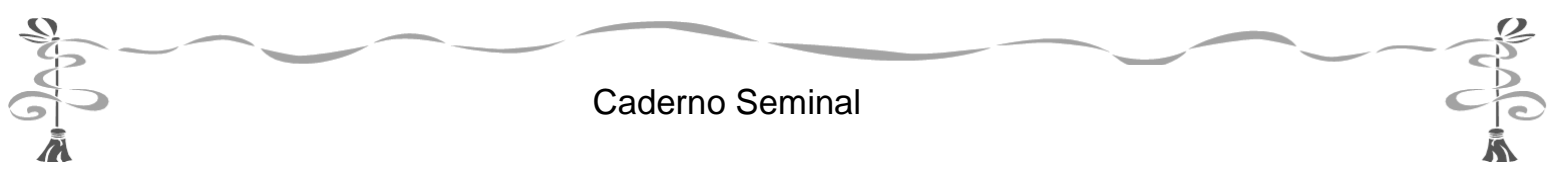

2008. Mas dois segmentos podem ser mais eloquentes no reforço desta visão de partilha planetária:

(12) E «nós», cidadãos, elemento decisivo da equação da sustentabilidade ambiental, económica e social, somos o tema central desta edição. (Visão, 2010, p. 5)

(13) A sustentabilidade ambiental é uma causa que a todos deve unir, num esforço coletivo indispensável para preservar a «casa» que todos partilhamos, a Terra. (Visão, 2011, p. 4)

O enunciador coloca-se, desta forma, ao lado do enunciatário, o que constitui não só uma estratégia de reforço da adesão à leitura, mas também (e sobretudo) uma estratégia de credibilização do enunciador, que lhe permita construir um ethos mais favorável à sua argumentação. Sabendo que o discurso a favor do ambiente e da sustentabilidade é, necessariamente, um discurso intromissivo na vida dos cidadãos, realizando frequentemente atos ilocutórios diretivos não impositivos, mas de força ilocutória potenciada por um discurso catastrofista, é fundamental que o seu enunciador ganhe credibilidade para os fazer legitimamente.

Numa perspetiva aristotélica, o ethos será composto de três dimensões: a competência / sabedoria, a honestidade / sinceridade e a benquerença / boa vontade (Amossy, 2010). Neste caso, a primeira decorrerá da autoridade oferecida pelo interdiscurso da ciência na enunciação do jornalista e pela capacidade por este demonstrada na sua mediação; a segunda decorrerá da própria organização do discurso, da sua clareza e conformidade à adequada relação com o leitor e com os fundamentos do assunto em causa; e a terceira do reconhecimento dos sentimentos positivos do jornalista, da sua atitude positiva face aos valores em causa. Ora, colocando-se ao lado do leitor como um seu par, assumindo que sofre com ele os mesmos riscos e que, como ele, estará disposto a empenhar-se na mesma luta, passando pelas mesmas dificuldades e adotando os mesmos compromissos, fazendo com o leitor um "nós", o seu ethos sairá reforçado e, portanto, a sua argumentação ganhará credibilidade, ou seja, a relação entre os seus argumentos e as conclusões para que estes se orientam receberá uma atmosfera favorável e potenciadora da eficácia.

Há que sublinhar que a feliz realização de atos ilocutórios diretivos não impositivos, como é o caso, nem sempre decorre de uma argumentação puramente racional (exclusivamente associada ao logos), mas sobretudo a uma adesão a uma determinada posição discursiva, que ultrapassa a racionalidade argumentativa pura e envolve outras dimensões, nomeadamente o ethos do enunciador. Naturalmente, como se

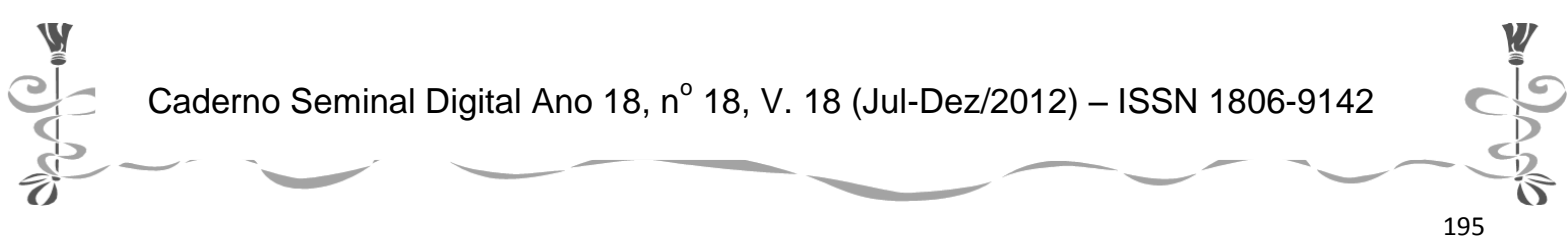




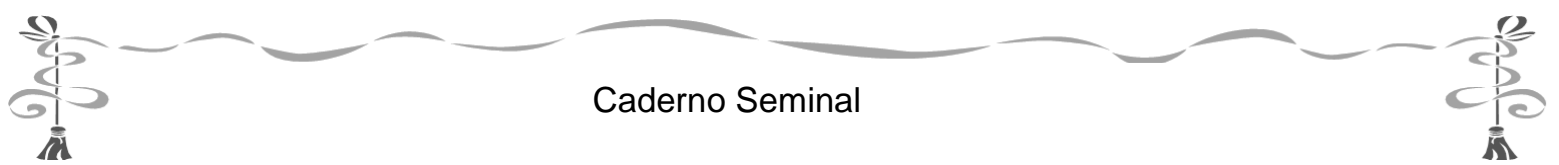

reconhece, esta conceção de argumentação afasta-se da visão aristotélica da Retórica e enquadra-se na perspetiva linguística da moderna Análise do Discurso ${ }^{101}$.

Os referidos atos ilocutórios diretivos têm a sua concretização discursiva em múltiplos segmentos, identificáveis desde a primeira frase do primeiro artigo analisado - o seu título:

(14) Por um Portugal Verde (Visão, 2007, p. 12)

Este título de tom panfletário exorta à ação, assumindo o objetivo pragmático de fazer-fazer, na medida em que sintetiza uma das funções pragmáticas do texto no seu todo. De facto, a organização textual desenvolve-se em vários momentos e linhas de força: abre com o retrato catastrófico do ambiente, tornado próximo e palpável pela evocação de manifestações violentas da natureza; assume que os cidadãos estão conscientes da necessidade de mudança; e apresenta, em seguida, como conclusão natural da leitura dos estados de coisas desenhados, um enunciado que manifesta um dos programas de ação que defende:

(15) Para evitar estes cenários catastróficos são necessários novos entendimentos entre os Estados, novos acordos políticos que garantam os patamares de entendimento mínimo para travar a degradação ambiental. Estamos a falar de várias mudanças em simultâneo, e todas elas «impossíveis»: nas estruturas industriais, nas fontes de energia, nos conceitos de soberania, nas regras do comércio internacional, na ajuda ao Terceiro Mundo, nos grandes interesses económicos e políticos de pequenos e grandes impérios. (Visão, 2007, p. 12)

De acordo com a organização retórica do texto, não parece que esta sequência se limite a realizar uma asserção, mais ou menos objetiva e isenta, mas um ato de incitamento - e exigência - à realização de uma ação, ou seja, verifica-se neste passo a realização de um ato diretivo, com força ilocutória decorrente da construção de uma realidade disfórica em alto grau. A este nível, não se tratará de uma ação direta de cada cidadão, impossibilitado de interferir pessoalmente nas estruturas industriais, nos acordos entre nações, etc.; mas trata-se de um exercício de influência, para que os cidadãos exijam dos seus representantes políticos esse rumo na gestão da coisa pública.

O artigo é, assim, configurado como visando uma polidestinação: se fala diretamente ao leitor cidadão comum, elegendo-o seu destinatário imediato, não deixa de escolher um outro destinatário, este já mediado, que é o decisor político, dependente da escolha coletiva dos cidadãos no exercício democrático. E, desta forma, incentiva o cidadão a exigir dos decisores políticos uma determinada postura.

${ }^{101}$ Cf.: Maingueneau, 1999; Amossy, 2010.

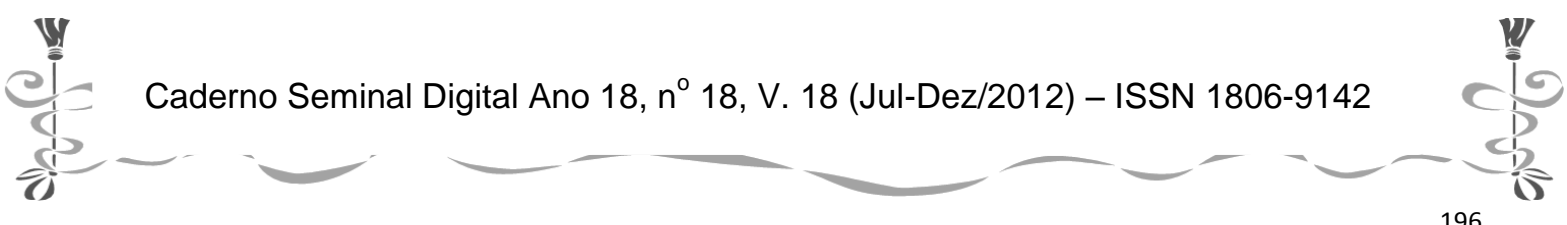




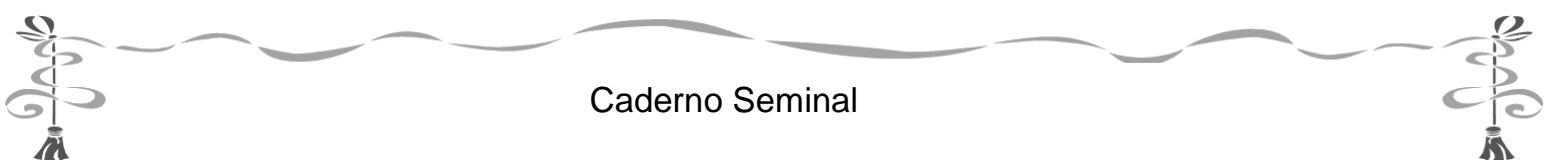

Há, contudo, no final do artigo, a realização de um ato ilocutório diretivo que assume como destinatário cada cidadão individual e pessoalmente considerado na sua ação quotidiana:

(16) (...) possam reforçar a mensagem fundamental desta VISÃO Verde: O Planeta Terra está mal e precisa de nós, mas nós precisamos ainda mais dele. (Visão, 2007, p. 13)

Completa-se, desta forma, um dos objetivos pragmáticos deste texto: incentivar à ação, e à ação individual, acessível a cada um nos grandes e nos pequenos gestos, objetivo anunciado, como referido acima, desde o título do artigo.

A focalização no indivíduo e sua ação é particularmente visível no texto de 2010, como é explicitamente assumido em (12), acima. Poderá afirmar-se que o foco sofreu uma alteração discreta dos grandes problemas vagos, do que os outros, lá longe, fazem, do que poderá ocorrer um dia, talvez, para se configurar a problemática das alterações climáticas em torno das ações de cada indivíduo, aqui, hoje. Tal é igualmente saliente no artigo (e no tema da edição) de 2009, centrado sobre a vida urbana, e no texto de 2011, que se centra sobre a agricultura, numa perspetiva muito próxima e de ação prática.

Esta centração no indivíduo não é nova no âmbito do ambientalismo. Contudo, poderá surgir uma interrogação sobre as possibilidades e os modos de conciliação entre conceções do mundo que privilegiam a defesa do bem comum, e portanto tendencialmente mais coletivistas, e aquelas que privilegiam a liberdade e a responsabilidade individuais, portanto tendencialmente mais individualistas.

\section{Utilitarismo e mercantilização do ambiente}

Contrariamente ao que poderia esperar-se de um discurso mais típico da ecologia profunda, ou de visões mais idealistas, nestes textos a questão ambiental é colocada em termos muito concretos, em particular nas últimas edições, como foi referido acima. De forma substancialmente expressiva nas edições de 2011 e 2012, o ambiente é configurado como recurso. Não é reconhecido à natureza um estatuto de bem intangível, não se discorre sobre os direitos dos seres vivos ou sobre os modelos de organização social desgarrados dos valores da mãe-Terra, por exemplo, mas apela-se muito pragmaticamente ao uso dos recursos como forma de subsistência. Um uso sustentável, naturalmente, mas ainda assim atribuindo-lhe um valor comercial, no que poderá ser apontado como uma mercantilização do ambiente:

(17) É preciso, pois, regressar à terra, para combater o endividamento externo e o desemprego, para aumentar a nossa capacidade de produzir, de criar riqueza, de exportar. E é preciso que tomemos à letra a necessidade de consumir português nesta altura de dificuldades. (Visão, 2011, p. 4)

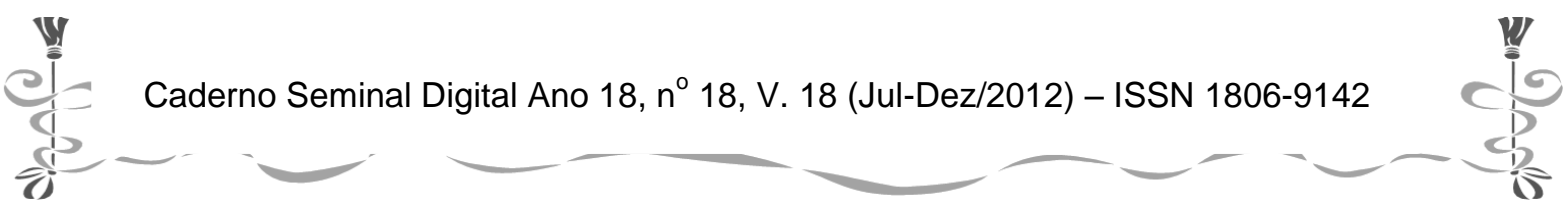




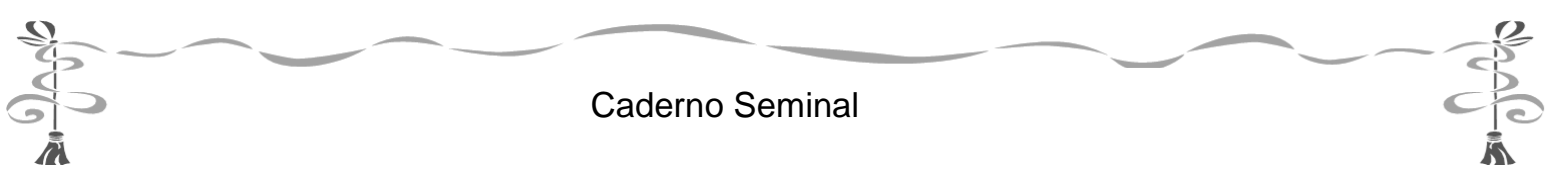

(18) E, nesta altura de crise profunda que atravessamos, achámos que fazia todo o sentido tentar perceber a dimensão desta riqueza que temos e de que forma a podemos estar a desperdiçar. (Visão, 2012, p. 5)

A perspetiva sobre a relação entre o homem e o meio é claramente antropocêntrica e este é encarado como meio-recurso. A motivação para a ação decorre mais dos imperativos económicos do que da adoção de valores de equilíbrio e harmonia com a natureza - ainda que, assinale-se, o fulcro seja a noção de sustentabilidade.

O artigo de 2012 tem mesmo um início muito expressivo:

(19) Sim, somos ricos

A afirmação, nos dias que correm, pode parecer absurda. Mas Portugal tem uma enorme riqueza. Ela resulta das condições que a natureza nos oferece (...), permitindo grande diversidade animal e vegetal e grande variedade de paisagens e climas, com zonas secas e zonas húmidas, áreas desérticas e densas florestas, planícies e montanhas, rios e mar. (...)

Portugal tem todas as condições para poder tirar o melhor partido desta riqueza. (Visão, 2012, p. 5)

Ainda que se trate de um uso metafórico, a identificação entre elementos naturais e "riqueza" não deixa de contabilizar, inventariar e avaliar financeiramente fauna, flora, paisagens, água, sol ou vento. Mesmo referentes não contáveis, como o clima ou o mar, adquirem um valor contável, materializado pela metáfora. Esta é desenvolvida desde o título, que encerra a estranheza (e, dela decorrente, o poder atrativo da atenção do leitor) da flagrante contradição com o discurso público vigente, avassaladoramente marcado pela crise financeira.

A mesma visão do mundo é manifestada nos restantes artigos, ainda que, eventualmente, de modo menos acentuado. Mas já a edição de 2008 apresentava um breve texto sob o título "Salvar o mar" que associava esse objetivo a valores económicos, concretizados nas "potencialidades e riquezas" do mar:

(20) Numa época marcada pela ameaça das mudanças climáticas, a defesa da vida nos oceanos e, em simultâneo, o aproveitamento sustentado das potencialidades e riquezas marítimas ganharam uma importância decisiva. (Visão, 2008, p. 6).

Trata-se, então, do apelo não a uma radical mudança de paradigma de vida, mas a uma adaptação a novas contingências de organização social e económica. Os argumentos de preservação por si, de equilíbrio numa escala planetária ou de comportamento ético independentemente de interesses pessoais parecem ser suplantados por outros menos universais e mais dependentes do desejo de bemestar pessoal.

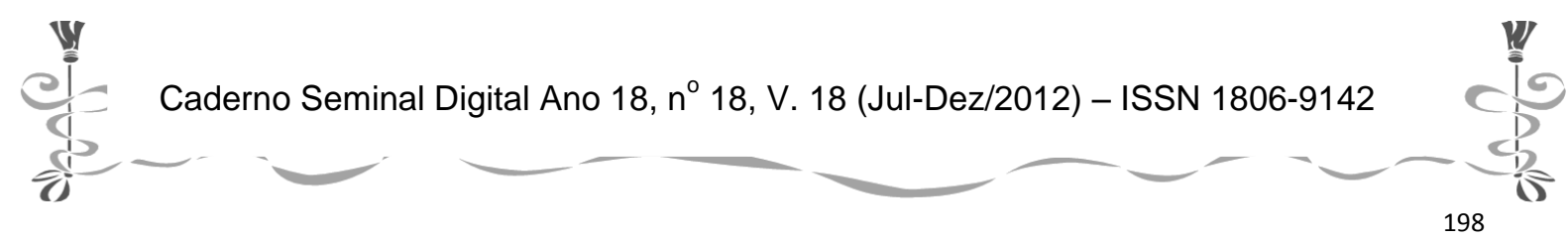




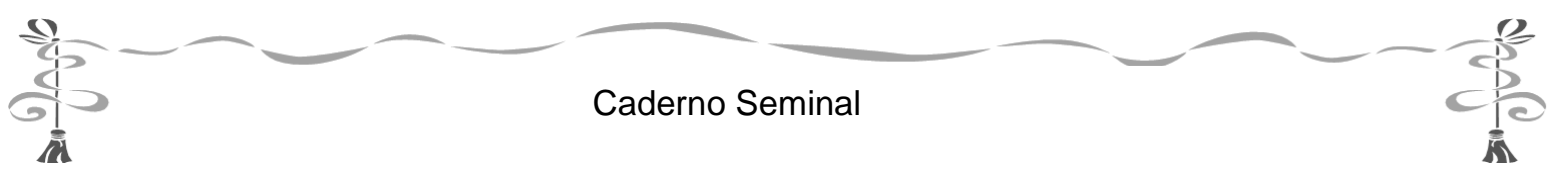

\section{Conclusões}

Em suma, pode constatar-se que os media generalistas, neste caso representados por seis edições especiais de uma revista de informação de grande difusão, veiculam o discurso ambiental, mantêm-no na esfera pública, dão-lhe vida e agendam o devir social. De alguma forma, dão continuidade ao discurso proveniente dos círculos especializados e dos ativistas, fazendo-o chegar ao grande público, genericamente mantendo temas recorrentes.

Este discurso incorpora caraterísticas do campo discursivo típico dos media, nomeadamente na sua busca do apelativo e do fantástico, recriando cenários catastróficos e de alto grau de intensidade. Esses cenários são particularmente visíveis no léxico, nível de superfície de forte poder identificador. A reificação dos estados de coisas por eles efetuada tem propósitos retóricos, permitindo ao cidadão interiorizar e operacionalizar realidades dificilmente experienciáveis pelos sentidos, sem a intervenção edificadora do discurso.

A ciência tem uma presença saliente, assumindo um papel de credibilização operativo num discurso que se projeta no futuro (e, portanto, necessariamente sujeito a algum grau de dúvida) e que apresenta uma dimensão pragmática diretiva, de exortação à ação (e, portanto, a exigir autorização do agente dos atos diretivos). Essa exortação tem um destinatário individual (cada cidadão, nos seus gestos quotidianos) e um destinatário institucional, indiretamente afetado (os decisores políticos, dependentes da eleição dos cidadãos).

A face agónica do discurso sobre o ambiente manifesta-se por um frame genérico que atribui à natureza o papel de vítima, trazendo traços do campo discursivo jurídico e da guerra, e reforça a criação de empatia entre o leitor e os elementos naturais.

O reconhecimento do enunciador como voz credível é igualmente uma estratégia identificável, pela valorização do ethos do jornalista, que ganha espaço para dar curso à referida diretividade do discurso ambiental.

Contudo, algum espaço de conflito subsiste, nomeadamente quanto à conceção das relações entre homem e ambiente, já que o utilitarismo ou a mercantilização do meio se manifestam de forma muito visível, o que constitui uma perspetiva polémica no seio do discurso ambiental.

A análise diacrónica do córpus permite afirmar que a reificação dos fenómenos naturais associada a casos concretos surge em 2007, mas tende a diluir-se ao longo dos anos. Nos tempos mais recentes, parece não ser tão necessário apontar fenómenos experienciáveis para convencer as pessoas, o que poderá querer dizer que houve um progresso no discurso ambiental: já não é preciso evocar o sabido, já não é preciso convencer ao nível intelectual, porque está assumido o papel do homem na destruição do equilíbrio ambiental; é só preciso apontar caminhos e

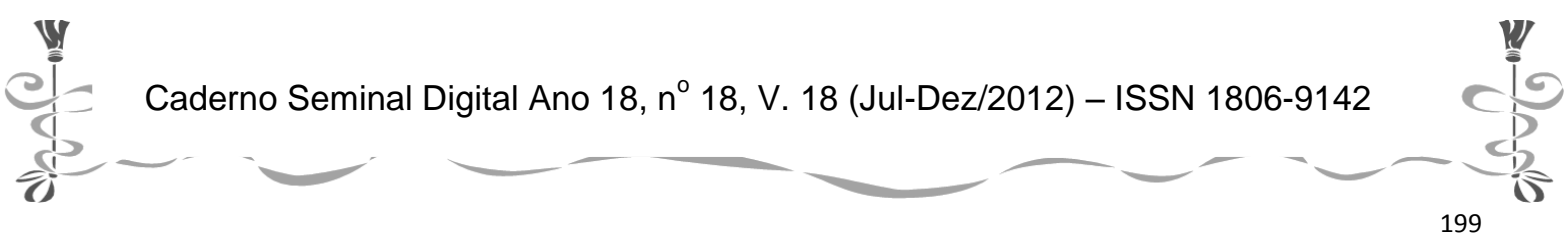




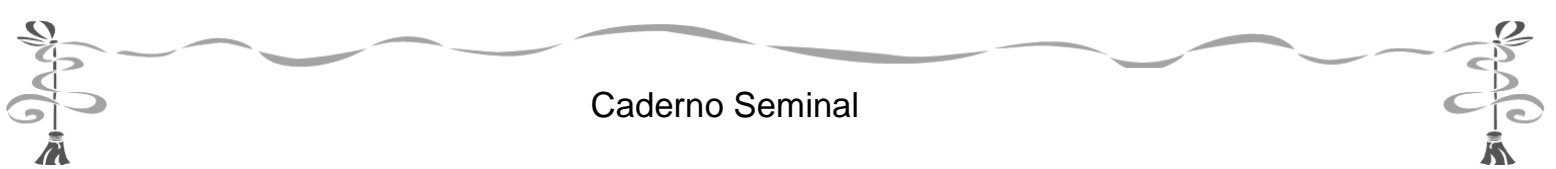

persuadir (não só argumentar), mover os espíritos e gerar ação concreta, ao nível coletivo e ao nível individual.

A ideia de desenvolvimento sustentável é basilar neste discurso que, apesar de todo o catastrofismo, se configura ainda como razoavelmente otimista, um discurso prospetivo de esperança que vê na adaptação às novas realidades uma resposta adequada aos problemas ambientais e aos problemas socioeconómicos.

\section{Referências}

Amossy, R. La présentation de soi. Ethos et identité verbale. Paris: PUF, 2010.

Bakhtine, M. (1981 (1930)) «La structure de l'énoncé». In T. Todorov: Mikhail Bakhtine et le principe dialogique, suivi de Écrits du Cercle de Bakbtine. Paris: Seuil, pp. 287-316.

Charaudeau, P. Le discours d'information médiatique. La construction du miroir social. Paris: Nathan, 1997.

Fonseca, J. (1994) "Dimensão accional da linguagem e construção do discurso". In . Pragmática Linguística. Introdução, Teoria e Descrição do Português, Porto: Porto Editora, pp. 105-131.

Foust, C. R. \& Murphy, W. (2009) "Revealing and Reframing Apocalyptic Tragedy in Global Warming Discourse". Environmental Communication: A Journal of Nature and Culture, 3: 2, pp. 151-167.

Harré, R., Brockmeier, J. \& Mühlhäusler, P. Greenspeak. A Study of Environmental Discourse. Thousand Oaks / London / New Delhi: Sage, 1999.

Jung, M. (2001) "Ecological Criticism of Language". In A. Fill \& P. Mühlhäusler (eds.) The ecolinguistics reader. Language, ecology and environment. London / New York: Continuum, pp. 270-285.

Koetsenruijter, W. (2008) "How numbers make news reliable". In L. Dam, L.-L. Holmgreen \& J. Strunck (Eds.) Rhetorical Aspects of Discourses in Present-Day Society. Newcastle upon Tyne: Cambridge Scholars Publishing, pp. 193-205.

Maingueneau, D. (1999) “Ethos, scénographie, incorporation”. In R. Amossy (ed.) Images de soi dans le discours. La construction de l'éthos. Lausanne: Delachaux et Niestlé, pp. 75-100.

Moirand, S. (1999) "Les indices dialogiques de contextualisation dans la presse ordinaire". Cabiers de praxématique, 33. pp. 145-184.

Ramos, R. O discurso do ambiente na imprensa e na escola. Uma abordagem linguística. Lisboa: Fundação Calouste Gulbenkian / Fundação para a Ciência e a Tecnologia, 2009.

Ramos, R. (2011) “Contributos para a caraterização da retórica ambiental na imprensa generalista portuguesa”. Revista Galega de Filoloxia, 12, pp. 155-176.

Ramos, R. \& Carvalho, A. (2008) "Science as Rhetoric in Media Discourses on Climate Change". In L. Dam, L.-L. Holmgreen \& J. Strunck (Eds.) Rhetorical Aspects of Discourses in Present-Day Society. Newcastle upon Tyne: Cambridge Scholars Publishing, pp. 223-247.

van Dijk, T. News as discourse. Hillsdale, New Jersey: Laurence Erlbaum, 1988.

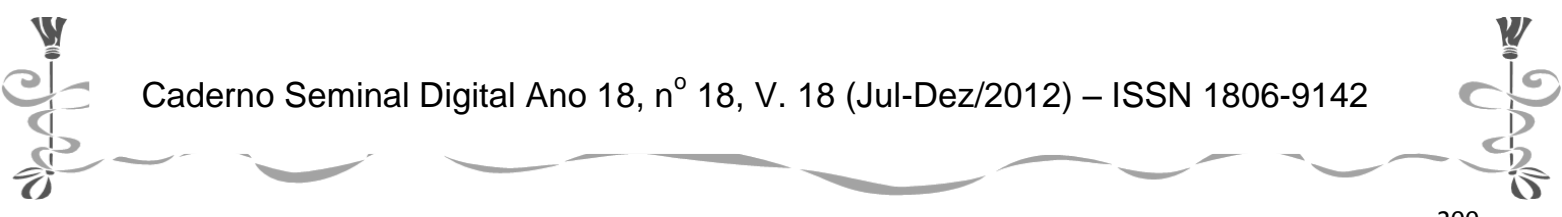




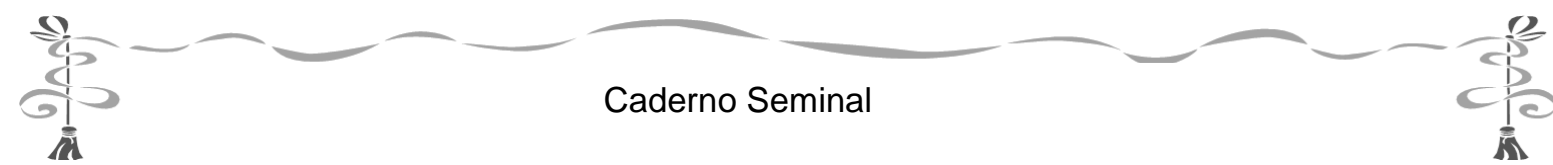

Outras fontes:

Maingueneau, D. L'ethos, de la rbétorique à l'analyse du discours, 2002 In http://dominique.maingueneau.pagesperso-orange.fr/intro company.html (acedido em $30 / 9 / 2012)$

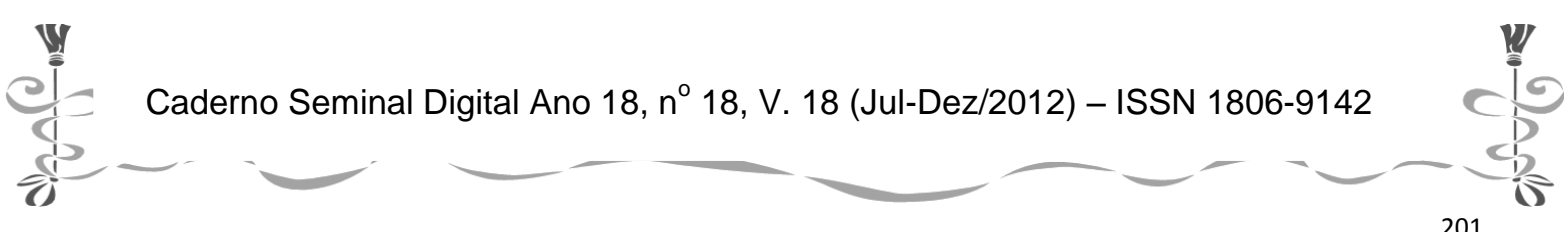

